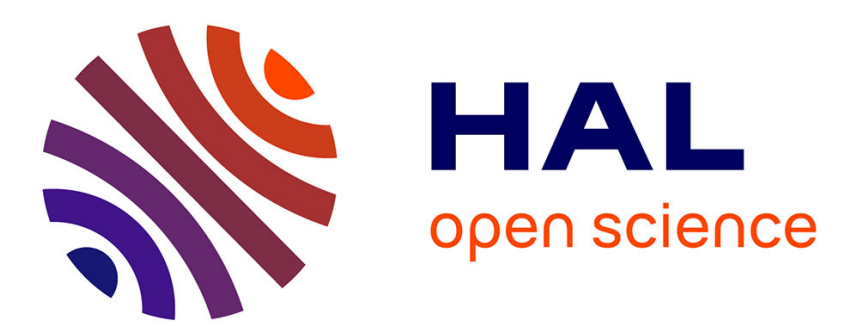

\title{
High electric field effects on the acrylonitrile molecule: an ab initio study
}

Michèle Raynaud, Cécile Reynaud, Yves Ellinger, Genevieve Hennico, Joseph Delhalle

\section{- To cite this version:}

Michèle Raynaud, Cécile Reynaud, Yves Ellinger, Genevieve Hennico, Joseph Delhalle. High electric field effects on the acrylonitrile molecule: an ab initio study. Chemical Physics, 1990, 142, pp.191 201. 10.1016/0301-0104(90)89080-A . hal-01949752

\section{HAL Id: hal-01949752 \\ https://hal.science/hal-01949752}

Submitted on 26 Dec 2020

HAL is a multi-disciplinary open access archive for the deposit and dissemination of scientific research documents, whether they are published or not. The documents may come from teaching and research institutions in France or abroad, or from public or private research centers.
L'archive ouverte pluridisciplinaire HAL, est destinée au dépôt et à la diffusion de documents scientifiques de niveau recherche, publiés ou non, émanant des établissements d'enseignement et de recherche français ou étrangers, des laboratoires publics ou privés. 
Chemical Physics 142 (1990) 191-201

North-Holland

\title{
HIGH ELECTRIC FIELD EFFECTS ON THE ACRYLONITRILE MOLECULE: AN AB INITIO STUDY
}

\author{
Michèle RAYNAUD, Cécile REYNAUD ${ }^{1}$ \\ CEA-Saclay, Service de Physique des Atomes et des Surfaces, Bâtiment 462, F-91191 Gif-sur-Yvette, France
}

\author{
Yves ELLINGER \\ Equipe d'Astrochimie Quantique, Laboratoire de Radioastronomie, Ecole Normale Supérieure, \\ 24 rue Lhomond, F-75005 Paris, France
}

\author{
Geneviève HENNICO and Joseph DELHALLE \\ Laboratoire de Chimie Théorique Appliquée, Facultés Universitaires, Universitaires Notre-Dame de la Paix, \\ 61 rue de Bruxelles, B-5000 Namur, Belgium
}

Received 18 September 1989

\begin{abstract}
The behaviour of a vinylic molecule (acrylonitrile) submitted to the high electric field occurring during cathodic polymerization has been investigated by ab initio calculations. In this approach the electrochemical double layer has been modelized by homogeneous fields (up to $2 \times 10^{10} \mathrm{~V} / \mathrm{m}$ ). It is found that the field induces minor geometrical deformations in the molecule ( $<4^{\circ}$ and $<0.02 \AA$ ). But, owing to its orientation along the $\mathrm{C}=\mathrm{N}$ bond, it enhances the electron attraction effect of the nitrile group, an intensity of $5 \times 10^{\circ} \mathrm{V} / \mathrm{m}$ being needed to induce on the vinylic bond an effect of the same order of magnitude as that of $\mathrm{CN}$ itself. An opposite $\sigma / \pi$ electron transfer is also pointed out, suggesting how important is the $\sigma-\pi$ separation in conjugated system when subjected to an external field. Very high field intensity $\left(10^{10} \mathrm{~V} / \mathrm{m}\right)$ is needed to induce significant changes in the electronic density and electrostatic potentials of the molecule, the particular behaviour of the highest occupied and lowest unoccupied molecular orbital (HOMO and LUMO) suggesting an increased ability for the $\mathrm{CH}_{2}$ group to attract electron rich functional groups when such a high field intensity is reached. Finally the position trans relative to the $\mathrm{CN}$ group is the one most affected by the electric field; this behaviour provides a clue for monitoring the electronic properties of the molecule in view of designing selective polymerization reactions.
\end{abstract}

\section{Introduction}

Theoretical studies of molecular systems subjected to the influence of external electric fields are not only of great theoretical interest but are also of practical significance for many investigations in physics and chemistry. The characteristic electric field strengths in field ionisation mass spectrometric experiments [1] are about $10^{9}-10^{10} \mathrm{~V} / \mathrm{m}$, while the field strengths achieved in classical electro-optic studies are in the range of $10^{6}-10^{7} \mathrm{~V} / \mathrm{m}$. In electrochemistry, strong

1 Permanent address: CEA-Saclay, Département des Lasers et de la Physico-Chimi, Bâtiment 522, F-91191 Gif-su-Yvette, France. fields estimated [2] to about $10^{9} \mathrm{~V} / \mathrm{m}$ are developed in the electrochemical double layer at the interface between the electrode and the solution.

The aim of this work is to evaluate how an electric field can favorise the opening of the $\pi_{\mathrm{C}-\mathrm{C}}$ double bond of an acrylonitrile $\left(\mathrm{CH}_{2}=\mathrm{CHCN}\right)$ monomer, in order to clarify the question of the role played by the electrochemical double layer in the cathodic polymerization [3]. Comparison of the field effect with the inductive effect of the $C \equiv N$ group on the $\pi_{C-C}$ bond is made through the study of the isoelectronic molecule $\mathrm{CH}_{2}-\mathrm{CHCCH}$. In a previous work [4], we have reported an ab initio study of the electric field effect on several molecules. Dipole moments, polarizabilities and atomic charges were considered for 
$\mathrm{HCN}, \mathrm{CH}_{3} \mathrm{CN}, \mathrm{CH}_{2} \mathrm{CHCN}, \mathrm{CH}_{2} \mathrm{C}(\mathrm{CN})_{2}$ and $\mathrm{CH}_{2} \mathrm{CHCCH}$ with homogeneous fields up to $2.056 \times 10^{9} \mathrm{~V} / \mathrm{m}(0.004 \mathrm{au})$. Our calculations have indicated non negligible polarizabilities, but the induced dipole moment was still weak comparatively to the permanent one. The better ability of the $\mathrm{C}=\mathrm{C}$ bond compared to $\mathrm{CN}$ to respond to the field solicitation has been stressed. An analysis of the Mulliken atomic charges has also shown small changes in the charge patterns compared to those usually induced by chemical substitution. Moreover the particular reactivity of the trans $\mathrm{CH}$ bond has been evidenced, suggesting that this position is the most appropriate one for tuning the molecular reactivity by substituent effects in the presence of an electric field.

The magnitude of the electric field developed in the electrochemical double layer is not accurately known; field intensities higher than $2 \times 10^{9} \mathrm{~V} / \mathrm{m}$ cannot be excluded in experimental situations, although they have never been reported; furthermore it is rather unprobable that such high fields can be homogeneous. Even in the absence of a more refined picture of this complex situation, the follow-up of the molecule electronic and structural characteristics under field intensities exceeding those generally admitted for electrochemical double layers is an interesting approach. This is why intensities up to $2.056 \times 10^{10} \mathrm{~V} /$ $\mathrm{m}$ have been considered in the present paper.

Our first work has clearly pointed out the limit of the analysis of global quantities such as dipole moments, polarisabilities and atomic charges in providing a definite answer to the question of the opening of the $\pi_{\mathrm{C}-\mathrm{C}}$ double bond when the molecule is subjected to the electric field. We present here a more detailed analysis of the changes induced in acrylonitrile. This paper is organised as follows: after a brief review of the computational aspect, we report the 3$21 \mathrm{G}$ optimized geometry of the molecule at $E=0$ and $2.056 \times 10^{10} \mathrm{~V} / \mathrm{m}$. The dependence of the computed values on the basis set extention is discussed, particularly the effect of adding higher quantum number functions owing to their importance in the Stark effect description. Then a detailed analysis of the acrylonitrile behaviour (induced dipole moment, Mulliken atomic charges, gross orbital and overlap populations) is made. In order to determine the role played by the high permanent dipole moment due to the $\mathrm{CN}$ group, comparison with an isoelectronic mol- ecule, $\mathrm{CH}_{2} \mathrm{CHCCH}$, is done. Finally, the deformations of the contour maps of the molecular orbital electronic density are discussed. Owing to their wellknown use for the prediction of the relative reactivity of functional groups in ionic-type reactions [5], electrostatic potentials have also been calculated.

\section{Computational aspects}

Results reported in this paper are obtained at the restricted Hartree-Fock level using the GAUSSIAN series of programs [6] to which a code for the finitefield [7] steps has been added. In this method, a term $-\boldsymbol{\mu} \cdot \boldsymbol{E}$ is added to the molecular Hamiltonian, where $\mu$ is the dipole moment vector of the molecule and $E$ the applied electric field vector.

In absence of external field, $E=0$, analytical gradient optimization techniques [8] have been employed to optimize fully the molecular geometry with the following requirements: $10^{-10}$ au for the twoelectron cutoff, $10^{-9}$ for the requested convergence on the density matrix elements, and $4.5 \times 10^{-4}$ hartree bohr ${ }^{-1}$ as maximal residual force for the Cartesian components of the gradient of the energy. In the case of geometry optimizations under external fields, the numerical Fletcher-Powell technique has been used, keeping the same constraints as above [9].

Computed values such as dipole moments, charges, overlap populations and electron densities obtained from the calculated molecular orbitals are known to depend on the basis set extension [10]. To have informations on this dependence, three basis sets have been used [11] namely the $3-21 \mathrm{G}, 6-31 \mathrm{G}^{*}$, and 6 $31 \mathrm{G}^{* *}$ basis sets.

Net atomic charges, gross orbital and overlap populations are reported in terms of Mulliken population analysis [12]. In order to compare the behaviour of the $\pi$ and the $\sigma$ electrons, we operate a partitioning of the electronic distributions: the $\pi$ contribution is reported as the $2 \mathrm{p}_{y}$ one (and $2 \mathrm{p}_{x}$ for the second $\pi_{\mathrm{CN}}$ orbital) and the $\sigma$ contribution has been computed as the total minus the is and $\pi$ contributions.

The electrostatic potential $V(r)$ arising from electronic and nuclear charge distributions of the molecule at every point in its surrounding space is given by [5] 
$V(\boldsymbol{r})=\int \frac{\Gamma\left(\boldsymbol{r}_{\mathrm{e}}\right)}{\left|\boldsymbol{r}-\boldsymbol{r}_{\mathrm{e}}\right|} \mathrm{d} \boldsymbol{r}_{\mathrm{e}}+\sum_{a} \frac{Z_{a}}{\left|\boldsymbol{r}-\boldsymbol{R}_{a}\right|}$,

where $\Gamma\left(r_{e}\right)$ is the electron charge distribution, i.e. the first-order density function determined in the SCF calculation. Electrostatic potentials have been computed and their contour maps drawn in selected planes.

\section{Results and discussion}

\subsection{Molecular geometry}

The structure of the molecule is shown in fig. 1 together with the notation used for the geometrical parameters. The molecular plane has been chosen to coincide with the $(z, x)$-plane, the $z$ axis being along the permanent dipole moment of the molecule ( $\alpha$ is the angle between the $\mathrm{CC}(\mathrm{N})$ axis and the total dipole moment vector). The electric field is imposed to lie in the molecular plane and oriented along $-z$. Zero-field equilibrium geometry parameters and total energies are given in table 1 for 3-21G and 6-31G* bases. These are in agreement with previously published experimental geometry [13] also reported in table 1.

When an electric field is applied to a molecule, the electron density reorganizes and a new equilibrium geometry is reached. It has been shown that electric field intensities of the order of $10^{10} \mathrm{~V} / \mathrm{m}$ are actually needed to induce noticeable geometrical changes in

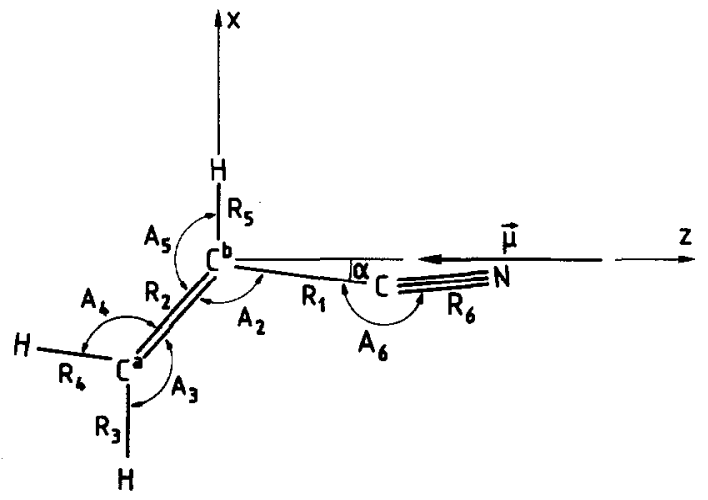

Fig. 1. Structure and notation used for the geometrical parameters of the acrylonitrile molecule. molecules, e.g., of the order of $0.01 \AA$ for bond length and a few degrees for bond angles [14]. In order to verify that the structural changes in acrylonitrile are also negligible, we have performed $3-21 \mathrm{G}$ gegmetry optimization with electric field intensity of $2.056 \times 10^{9}, 1.028 \times 10^{10}$ and $2.056 \times 10^{10} \mathrm{~V} / \mathrm{m}$. Therefore, only the results for the highest field are reported in table 1 . We observe a bond increase smaller or equal to $0.018 \AA$ for a $2.056 \times 10^{10} \mathrm{~V} / \mathrm{m}$ field. The unsaturated bonds $C=C$ and $C \equiv N$ are the most sensitive ones together with the trans $\mathrm{CH}$ bond, owing to its particular orientation nearly parallel to the field. Bond angles change by a few degrees. These geometrical modifications are rather small and in agreement with previously mentioned works.

From an orientational point of view, the isolated molecule in its non-zero-field equilibrium geometry is so that its total dipole moment lies parallel and in the direction of the field. As the field intensity increases, the angle between the $\mathrm{CC}(\mathrm{N})$ axis and the dipole moment vector, $\alpha$, although small, increases from $7.05^{\circ}$ at $E=0$ to $15.14^{\circ}$ at $E=2.05610^{10} \mathrm{~V} / \mathrm{m}$ (see table 1). At the same time, an increase of the $\mathrm{CCN}$ bond angle, $A_{6}$, and of the CCC one, $A_{2}$, is observed, pointing to a contribution of the $\mathrm{C}=\mathrm{C}$ double bond to the total dipole moment increasing with the field.

Accordingly, as already done in ref. [4], all results reported in the next sections correspond to the zerofield equilibrium geometry (except the $\mathrm{CCN}$ bond angle which has been kept to $180^{\circ}$ ), and the field is imposed to be parallel to the $\mathrm{C} \equiv \mathrm{N}$ group and oriented from $\mathrm{N}$ to $\mathrm{C}$.

\subsection{Basis effects}

In our previous work [4], we have shown how a basis of at least split valence quality is necessary to provide values in agreement with the experimental data. The question here is the dependence of the computed atomic charges and dipole moments on the basis set extension when adding polarization functions which are the next higher quantum number orbitals implied in the Stark effect. Two series of computations were done: (i) on $\mathrm{CH}_{2} \mathrm{CHCN}$, with two split-valence basis sets, namely: $3-21 \mathrm{G}$ and $6-31 \mathrm{G}^{*}$, using the corresponding geometries optimized at $E=0$ and (ii) on $\mathrm{HCN}$, with $6-31 \mathrm{G}^{*}$ and $6-31 \mathrm{G}^{* *}$ basis 
Table 1

Experimental and calculated geometrical parameters of $\mathrm{CH}_{2}=\mathrm{CHC}=\mathrm{N}$ (as defined in fig. 1). $R_{i}:$ distance in $\dot{\AA}, A_{i}$ and $\alpha$ : angle in degree, $E_{\mathrm{T}}$ : total SCF energy in au

\begin{tabular}{|c|c|c|c|c|}
\hline & \multirow[t]{2}{*}{ Exp. [11] } & \multicolumn{2}{|l|}{$3-21 \mathrm{G}$} & \multirow{2}{*}{$\begin{array}{l}6-31 \mathrm{G}^{*} \\
E=0\end{array}$} \\
\hline & & $E=0$ & $E=2.056 \times 10^{10} \mathrm{~V} / \mathrm{m}$ & \\
\hline$R_{1}$ & 1.426 & 1.427 & 1.428 & 1.443 \\
\hline$R_{2}$ & 1.339 & 1.319 & 1.337 & 1.320 \\
\hline$R_{3}$ & 1.086 & 1.072 & 1.073 & 1.074 \\
\hline$R_{4}$ & 1.086 & 1.071 & 1.080 & 1.074 \\
\hline$R_{5}$ & 1.086 & 1.072 & 1.074 & 1.074 \\
\hline$R_{6}$ & 1.164 & 1.140 & 1.154 & 1.136 \\
\hline$A_{2}$ & 122.61 & 122.69 & 126.45 & 122.14 \\
\hline$A_{3}$ & 121.73 & 121.73 & 124.04 & 121.89 \\
\hline$A_{4}$ & 121.73 & 121.89 & 120.49 & 120.72 \\
\hline$A_{5}$ & 121.73 & 120.95 & 119.12 & 122.03 \\
\hline$A_{6}$ & & 180.19 & 184.54 & $180.00^{\mathrm{a})}$ \\
\hline$\alpha$ & & 7.05 & 15.14 & 6.88 \\
\hline $\boldsymbol{E}_{\mathrm{T}}$ & & -168.8204 & -168.9248 & -169.7680 \\
\hline
\end{tabular}

a) Non optimised value.

sets, using the $6-31 \mathrm{G}^{*}$ geometry optimized at $E=0$, in order to test the effect of successively adding polarization functions first on heavy atoms $\left(6-31 \mathrm{G}^{*}\right)$ and then on hydrogens $\left(6-31 \mathrm{G}^{* *}\right)$.

For the sake of not overloading the presentation, we will only report the main conclusion. With these three basis sets, we observed the same trends in the evolution of the computed values (dipole moment and Mulliken populations ) with the field intensity, the fluctuations not exceeding $15 \%$. In the case of acrylonitrile, the relative increase of the dipole moment is nearly the same in the $3-21 \mathrm{G}$ basis $(\delta \mu /$ $\left.\mu^{0}=118.11 \%\right)$ than in the $6-31 \mathrm{G}^{*}$ ones $(\delta \mu /$ $\left.\mu^{0}=119.45 \%\right)$. For this molecule, the Mulliken population analysis in the $6-31 \mathrm{G}^{*}$ basis compared to that in the 3-21G one reveals net increase in the $\sigma$-overlap population: $35 \%$ for the $\mathrm{C}=\mathrm{C}$ bond, $30 \%$ on the $\mathrm{C} \equiv \mathrm{N}$ bond and a factor of 1.5 for the $-\mathrm{C}-\mathrm{C} \equiv$ bond. Similarly, the $\pi$-overlap population of the $\mathrm{C}-\mathrm{C} \equiv$ bond increases by a factor of three. These results reflect the better ability for the $6-31 G^{*}$ basis to concentrate the electrons in the $\sigma$ bonding region and to account for the conjugative effect through the $-\mathrm{C}-\mathrm{C} \equiv$ bond.

Comparison of $6-31 \mathrm{G}^{*}$ and $6-31 \mathrm{G}^{* *}$ results on $\mathrm{HCN}$ pointed to minor changes when adding polarization functions on hydrogen atoms. Similar trends were also observed in the case of the dipole moment.

Thus, the remaining differences between the ex- perimental geometry and dipole moment and the corresponding calculated values (tables 1 and 2) are in the range of the usual residual basis set deficiency (lack of diffuse functions for example) and most probably in the neglect of correlation effects.

According to the previous discussion, the inclusion of polarization functions in the atomic basis appears to be essential for a correct description of the electronic distribution. Addition of extra functions of lower exponent, which would improve the numerical accuracy but certainly not modify the basic properties we are looking at, was not deemed necessary at this level of theory. In the next section, we present the results obtained on $\mathrm{CH}_{2} \mathrm{CHCN}$ at the $6-31 \mathrm{G}^{*}$ level, with field intensities of $0,2.056 \times 10^{9}, 1.028 \times 10^{10}$ and $2.056 \times 10^{10} \mathrm{~V} / \mathrm{m} \quad(0.004,0.02,0.04 \mathrm{au}$ respectively).

\subsection{Dipole moment}

The components of the total dipole moment vector of $\mathrm{CH}_{2} \mathrm{CHCN}$ and its absolute value $|\boldsymbol{\mu}|$ are listed in table 2 for the four values of the field intensity considered. In our previous work [4], the study of the variation of the dipole moment with field intensity up to $2.056 \times 10^{9} \mathrm{~V} / \mathrm{m}$ has shown: (i) a linear response of $|\mu(E)|$ with the field (for the range of intensity used) and (ii) an induced dipole moment 
Table 2

Components and absolute value of the total dipole moment of $\mathrm{CH}_{2}-\mathrm{CHC}=\mathrm{N}$ for different field intensities at the 6-31G* level. $\mu$ : dipole moment in debye $\left(1 \mathrm{D}=3.33 \times 10^{-30} \mathrm{C} \mathrm{m}\right)$

\begin{tabular}{lcccc}
$E(\mathrm{~V} / \mathrm{m})$ & 0 & $2.056 \times 10^{9}$ & $1.028 \times 10^{10}$ & $2.056 \times 10^{10}$ \\
$\mu_{x}$ & 0.510 & 0.604 & 0.980 & 1.454 \\
$\mu_{z}$ & -4.256 & -4.752 & -6.708 & -9.225 \\
$|\boldsymbol{\mu}|$ & $4.256^{1)}$ & 4.761 & 6.779 & 9.229 \\
\hline
\end{tabular}

2) To be compared with the experimental value of $3.87 \mathrm{D}$ from ref. [15].

equal to about $10 \%$ (at $2.056 \times 10^{9} \mathrm{~V} / \mathrm{m}$ ) of the permanent one $(4.256 \mathrm{D})$ with a non-negligible component originating from the $\mathrm{C}=\mathrm{C}$ bond.

For the field intensity that we have considered here ( see table 2), a considerable increase of $|\boldsymbol{\mu}(E)|$ (a factor of two for $E=2.056 \times 10^{10} \mathrm{~V} / \mathrm{m}$ ) is observed, still corresponding to a linear dependence with the field intensity. Moreover, $\left|\mu_{x}\right|$ increases more than the $\left|\mu_{x}\right|$ component ( $185 \%$ and $117 \%$ respectively) which shows that the contribution of the $\mathrm{C}=\mathrm{C}$ double bond to the dipole moment becomes more important. For the highest field intensity these results are indicative of a very high charge transfer towards the nitrogen atom.

\subsection{Population analysis}

To get a more detailed picture of the changes in the molecular wavefunction, we have considered its Mulliken population analysis [12] which involves a partitioning of the charge distribution into atomic orbital contributions. In spite of its dependence on the number and type of atomic orbitals, the relative values of the Mulliken charges and overlap populations in a molecule are known to reproduce the essential features and trends of the electron distribution, although little significance can be attached to the magnitudes themselves [16]. The atomic charges evolution with the field intensity is reported in fig. 2 and table 3.

Before discussing the field effect, it is interesting to analyse the values computed in the zero-field situation. The polarization of the $\pi_{\mathrm{C}-\mathrm{C}}$ bond by the high dipole moment of the $\mathrm{CN}$ substituent group is already important. A quantitative idea of this polarization is obtained by comparing the charge transfer in $\mathrm{C}^{a} \mathrm{H}_{2} \mathrm{C}^{\mathrm{b}} \mathrm{HCN}$ (1) and in the isoelectronic molecule $\mathrm{C}^{a} \mathrm{H}_{2} \mathrm{C}^{b} \mathrm{HCCH}(2)$, where the substituent group

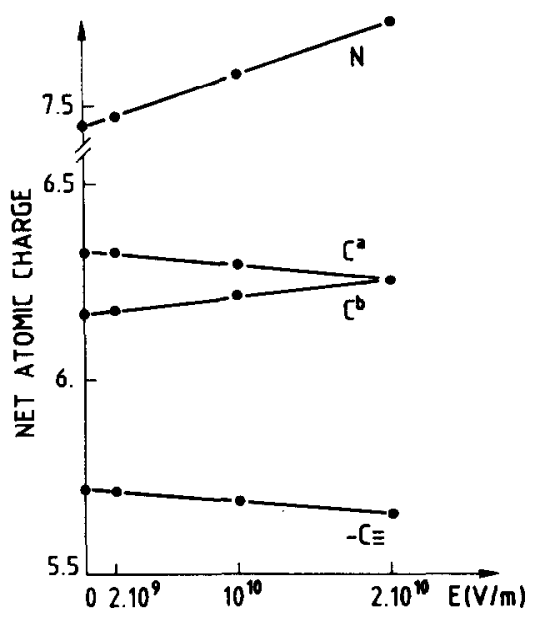

Fig. 2. Evolution of the Mulliken atomic charge of the molecule with the field intensity.

carries a much smaller dipole moment $(0.187 \mathrm{D})$. The data reported in table 3 show that the charge transfer from the $\mathrm{CH}_{2}=\mathrm{CH}$ moiety to the $\mathrm{CN}$ group is higher by 0.094 than that induced by the $\mathrm{CCH}$ group. The net result is a reversal of the $\mathrm{CH}_{2}=\mathrm{CH}$ bond polarity, defined as the difference between the net charge of the $\mathrm{CH}_{2}$ group and the $\mathrm{CH}$ one, equal to -0.015 for (2) compared to 0.025 for (1), which means a global transfer of 0.040 electron. This effect is essentially important on the $\mathrm{C}^{\mathrm{a}}\left(\mathrm{CH}_{2}=\right)$ atom, indeed: $q\left(\mathrm{C}_{(2)}^{\mathrm{a}}\right)-q\left(\mathrm{C}_{(1)}^{\mathrm{a}}\right)=0.026$ and $q\left(\mathrm{C}_{(2)}^{\mathrm{b}}\right)-$ $q\left(C_{(1)}^{b}\right)=-0.002$.

Atomic charges depend linearly upon the field intensities considered in this work. When the field increases, charges on $\mathrm{C}^{\mathrm{a}}$ and $\mathrm{C}^{\mathrm{b}}$ tend to equalize (fig. 2 ). The net charge on the $\mathrm{CH}_{2}$ group becomes more positive and that on $\mathrm{CN}$ becomes more negative (of about the same absolute value) while that on $\mathrm{CH}$ is nearly constant (table 3 ). From these results, we can 
Table 3

Mulliken charges on the carbon atoms of the $C^{a}=C^{b}$ bond and summation of the Mulliken net charge over the functional groups of $\mathrm{CH}_{2} \mathrm{CHCN}$ and $\mathrm{CH}_{2} \mathrm{CHCCH}$ for different field intensities at the 6-31G* level

\begin{tabular}{|c|c|c|c|c|c|}
\hline \multirow[t]{2}{*}{$E(\mathrm{~V} / \mathrm{m})$} & \multicolumn{5}{|c|}{$\mathrm{CH}_{2} \mathrm{CHCCH}$} \\
\hline & $\mathrm{C}^{\mathrm{a}}$ & $\mathrm{C}^{\mathrm{b}}$ & $\mathrm{C}^{\mathbf{a}} \mathrm{H}_{2}$ & $\mathrm{C}^{b} \mathrm{H}$ & $\mathrm{CCH}$ \\
\hline 0 & 6.361 & 6.171 & 0.030 & 0.045 & -0.075 \\
\hline \multirow[t]{2}{*}{$E(\mathrm{~V} / \mathrm{m})$} & \multicolumn{5}{|c|}{$\mathrm{CH}_{2} \mathrm{CHCN}$} \\
\hline & $\mathrm{C}^{\infty}$ & $\mathrm{C}^{\mathrm{b}}$ & $\mathrm{C}^{a} \mathrm{H}_{2}$ & $\mathrm{C}^{b} \mathrm{H}$ & $\mathrm{CN}$ \\
\hline 0 & 6.336 & 6.173 & 0.097 & 0.072 & -0.169 \\
\hline $2.056 \times 10^{9}$ & 6.331 & 6.182 & 0.119 & 0.071 & -0.190 \\
\hline $1.028 \times 10^{10}$ & 6.304 & 6.220 & 0.211 & 0.065 & -0.275 \\
\hline $2.056 \times 10^{10}$ & 6.263 & 6.261 & 0.324 & 0.065 & -0.389 \\
\hline
\end{tabular}

conclude that the field, owing to its orientation, enhances the electron withdrawing effect of the $\mathrm{CN}$ group on the $\mathrm{C}=\mathrm{C}$ double bond. Compared to the zero field situation, the increase of the bond polarity of $\mathrm{CH}_{2}=\mathrm{CH}$, defined as above, due to the field of $2.056 \times 10^{9} \mathrm{~V} / \mathrm{m}$ is equal to 0.023 ; thus a field intensity at least equal to $5 \times 10^{9} \mathrm{~V} / \mathrm{m}$ is needed to create an additional effect of the same order as that induced by the $\mathrm{CN}$ group itself.

A finer breakdown of the charge distribution in $\sigma$ and $\pi$ atomic orbitals has been made to get more precise information about the charge flux in the molecule. The evolution with the field intensity of the $\sigma$ and $\pi$ Mulliken gross orbital population is reported in fig. 3. When the field is applied, there is a strong two-way charge transfer between the $\sigma$ and $\pi$ electronic distributions, the $\sigma$ electrons being polarized opposite to the electric field direction and the charge shift being larger for $\pi$ electrons.

To complete this description, we report in figs. 4 and 5 the $\pi$ and $\sigma$ overlap populations (denoted OP). At the zero-field level, we find the expected behaviour of the $\sigma$ and $\pi$ bonds: $\mathrm{OP}_{\mathrm{CN}}^{\mathrm{a}}>\mathrm{OP}_{\mathrm{C}-\mathrm{C}}^{\mathrm{\sigma}}>\mathrm{OP}_{\mathrm{C}-\mathrm{C}}^{\mathrm{\sigma}}$ and $\mathrm{OP}_{\mathrm{CN}}^{\pi} \approx \mathrm{OP}_{\mathrm{CN}}^{\pi^{\prime}}>\mathrm{OP}_{\mathrm{C}-\mathrm{C}}^{\pi}$ in accordance with the reported bond length $\left(r_{\mathrm{CN}}<r_{\mathrm{C}-\mathrm{C}}<r_{\mathrm{C}-\mathrm{C}}\right)$.

As the field intensity increases, three different situations appear in the molecule backbone.

(i) For the $\mathrm{C}-\mathrm{C}$ bond, there is a general decrease of both the $\sigma$ and $\pi$ overlap populations corresponding to the lengthening of this bond as predicted by the geometry optimization.

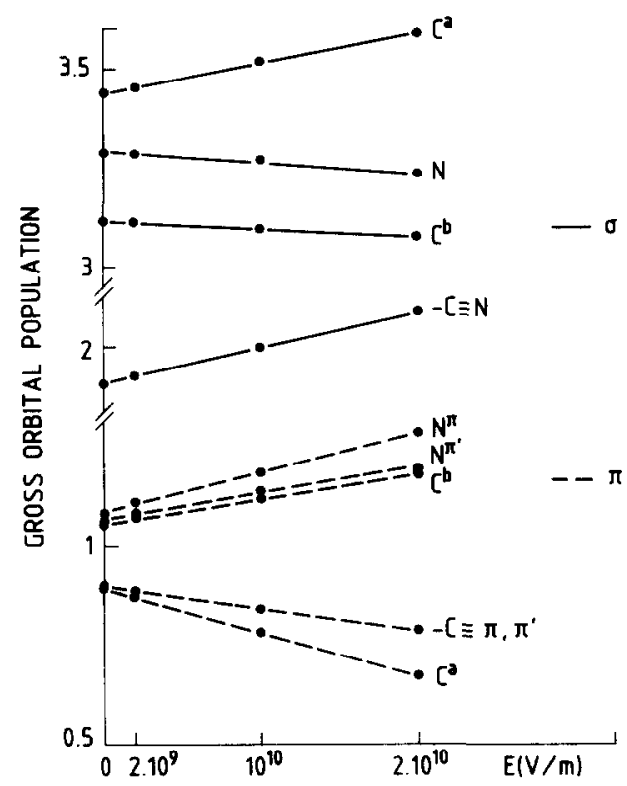

Fig. 3. Evolution of the gross orbital population $\sigma$ (continuous lines) and $\pi\left(2 \mathrm{p}_{y}\right)\left(\pi^{\prime}\left(2 \mathrm{p}_{x}\right)\right)$ (dashed lines) of the molecule with the field intensity.

(ii) For the C-C bond, we see at the same time, an increase of the $\pi$-conjugation but a stronger decrease of the $\sigma$ overlap population corresponding to the overall lengthening of this bond.

(iii) For the $\mathrm{C}=\mathrm{N}$ bond, the overlap population of the in plane $\pi^{\prime}$ orbital is not affected due to the lack 


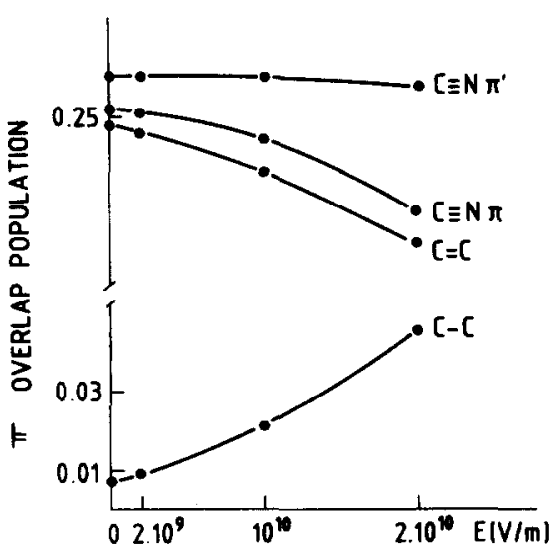

Fig. 4. Evolution of the $\pi\left(2 p_{y}\right)\left(\pi^{\prime}\left(2 p_{x}\right)\right)$ overlap population of the molecule with the field intensity.

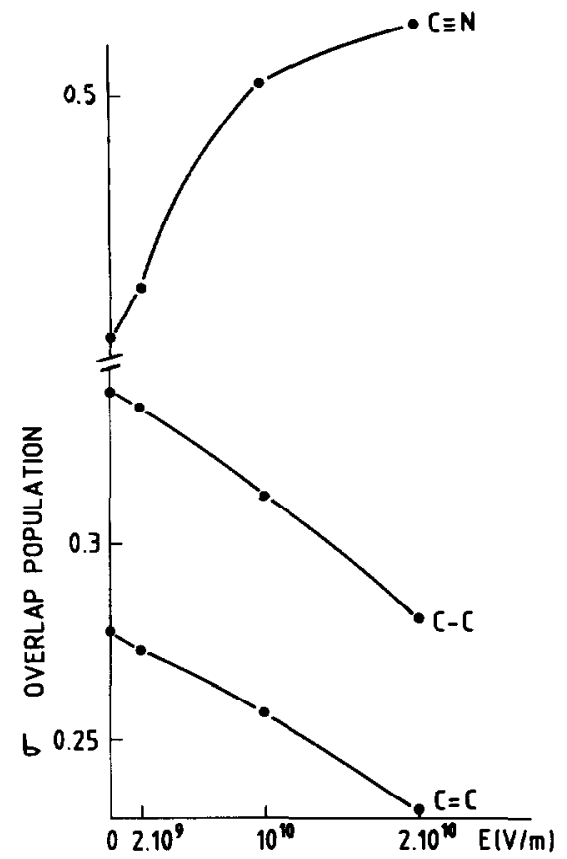

Fig. 5. Evolution of the $\sigma$ overlap population of the molecule with the field intensity.

of possible conjugation. The $\pi$ overlap population decreases whereas the $\sigma$ component shows a net increase. This latter behaviour is somewhat artificial since most of that value comes from a reorganisation of the nitrogen lone pair which explains that in the end there is a slight increase in the $\mathrm{CN}$ bond length.

The principal information drawn from this analysis is that the $\pi$ system has been pulled toward the nitrogen atom with a loss in the double bond character of the vinylic fragment and that this evolution is not linear with the field, an enhancement of this phenomenon being visible at $10^{10} \mathrm{~V} / \mathrm{m}$ (fig. 5 ).

\subsection{Electronic densities}

Owing to the basic limitation of the population analysis in reporting all information into atomic centered quantities, we further analysed the field effects
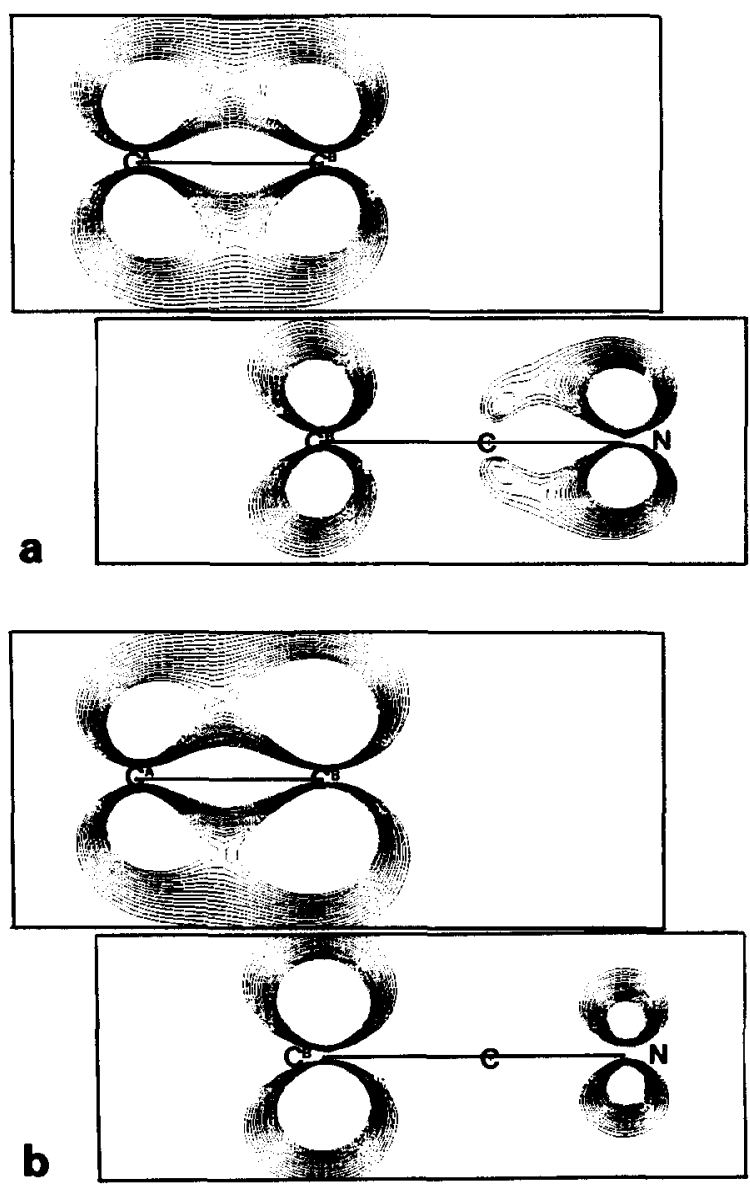

Fig. 6. Contour maps of the electronic density for the HOMO for: (a) $E=0$ and (b) $E=2.056 \times 10^{10} \mathrm{~V} / \mathrm{m}$. The upper and lower panels correspond to a cut in the $\pi_{\mathrm{C}-\mathrm{C}}$ and $\pi_{\mathrm{C}-\mathrm{N}}$ planes respectively. 

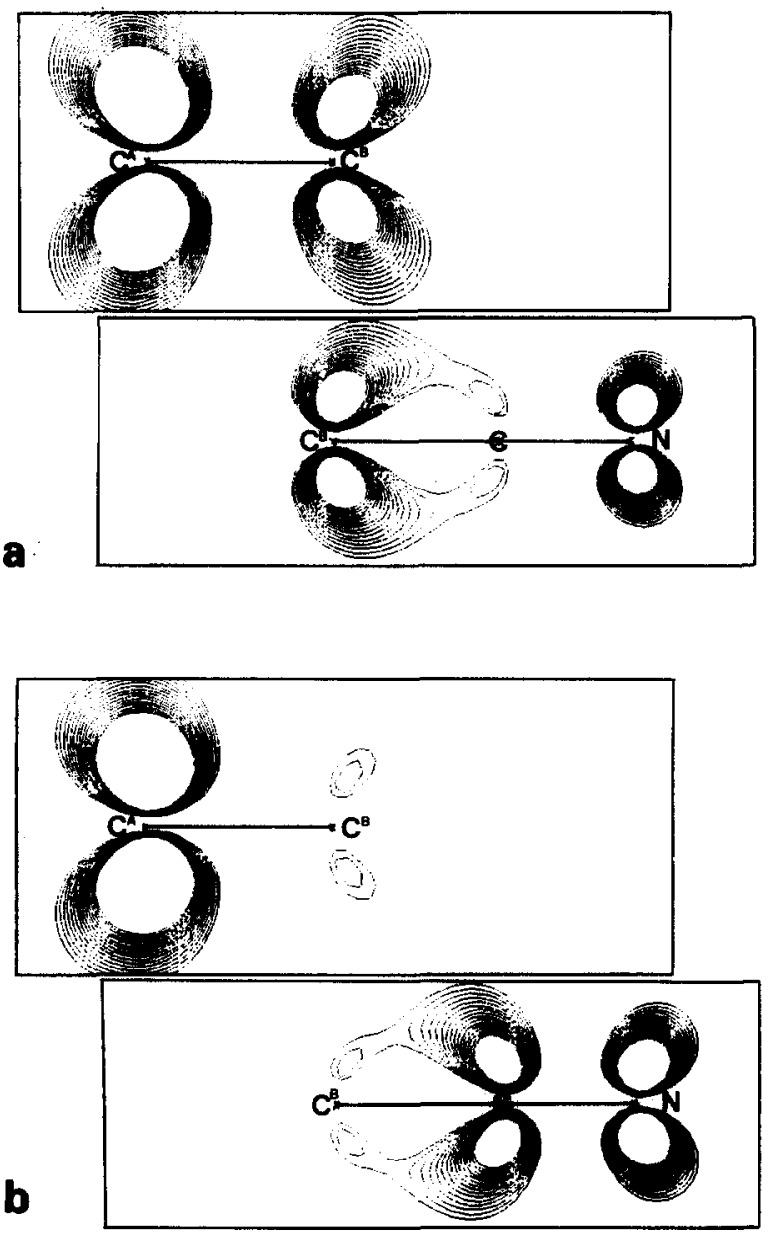

Fig. 7. Contour maps of the electronic density for the LUMO for: (a) $E=0$ and (b) $E=2.056 \times 10^{10} \mathrm{~V} / \mathrm{m}$. The upper and lower panels correspond to a cut in the $\pi_{\mathrm{C}-\mathrm{C}}$ and $\pi_{\mathrm{C}-\mathrm{C}-\mathrm{NN}}$ planes.

by probing the spatial distribution of the electron density. For the lowest field intensity studied here $\left(2.056 \times 10^{9} \mathrm{~V} / \mathrm{m}\right)$, the deformation of the electron density is actually weak. Fields higher than $10^{10} \mathrm{~V} /$ $\mathrm{m}$ are needed to induce noticeable changes.

According to the importance of the frontier orbitals for chemical reactivity [17] we considered the spatial distribution within the highest occupied molecular orbital (HOMO) and the lowest unoccupied one (LUMO) which have both a $\pi_{\mathrm{C}-\mathrm{C}}$ character for the zero field value. The contour maps of the HOMO and the LUMO, respectively, are reported for the highest and the zero-field intensity in figs. 6 and 7 in selected $\pi$ planes. The spatial distribution around the $\mathrm{C}^{\mathrm{a}}$ and $\mathrm{N}$ atoms appears to be less sensitive to the field than that of the $\mathrm{C}^{\mathrm{b}}$ and $\mathrm{C}(\mathrm{N})$ atoms. The HOMO's density increases around $\mathrm{C}^{\mathrm{b}}$, decreases around $\mathrm{C}^{\mathrm{a}}$ and $\mathrm{N}$ and becomes almost zero around $\mathrm{C}(\mathrm{N})$, supporting the idea of an increase in the nucleophilic character of $\mathrm{C}^{\mathrm{b}}$. As expected, the LUMO appears more sensitive to the field than the HOMO. A strong decrease is observed on $\mathrm{C}^{\mathrm{b}}$ together with an increase on $\mathrm{C}(\mathrm{N})$ and $\mathrm{N}$.

To complete this discussion, it can be added that increasing the electric field favours the interaction between the HOMO of a first monomer and the LUMO of a second one (interaction occurring during the polymerization ) in two ways: first, the energy gap between the orbitals decreases from $13.62 \mathrm{eV}$ at zero field to $13.43 \mathrm{eV}$ at $2 \times 10^{10} \mathrm{~V} / \mathrm{m}$; second, the reorganisation of the LUMO orbital results in a more efficient overlap between $\mathrm{C}^{\mathrm{b}}$ (HOMO of monomer 1 ) and $C^{a}$ (LUMO of monomer 2) leading to an easier opening of the $\mathrm{CC}$ double bond.

Contour maps in the plane of the molecule of the difference of the total electronic densities at the highest field $\left(2.056 \times 10^{10} \mathrm{~V} / \mathrm{m}\right)$ and the zero-field intensities are also reported in fig. 8. We observe an opposite deformation of the electronic density compared to those in $\pi$ planes. The most striking electron transfer, however, happens for the $\mathrm{CH}$ bond trans to the

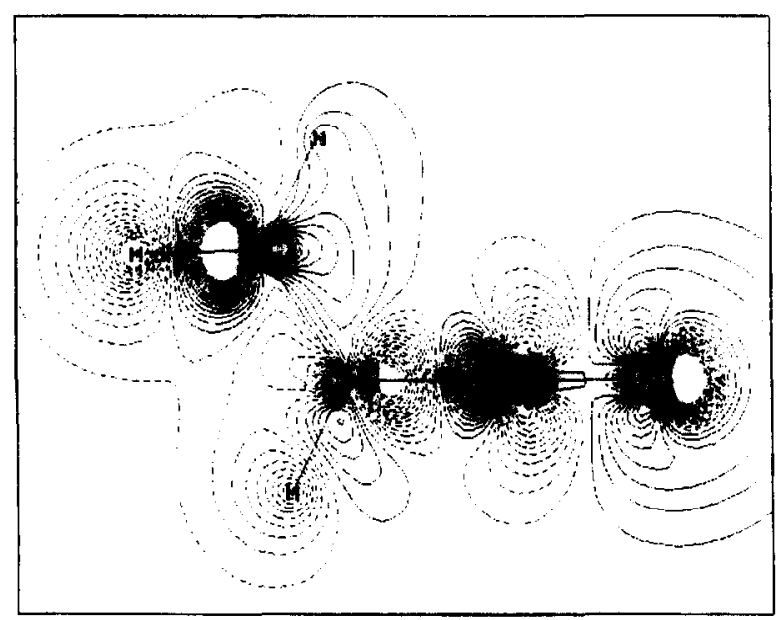

Fig. 8. Contour maps of the electronic difference density (from zero to $2.056 \times 10^{10} \mathrm{~V} / \mathrm{m}$ field intensity) for the summation of all the $\Phi$ in the planes. 
cyano group, providing a clear indication as to the most sensitive position to be substituted for imposing specific changes to the electronic distribution.

\subsection{Electrostatic potentials}

Our purpose here is to have information on the ex- perimental situation where the monomer is a target attacked by positively or negatively charged species.

At the zero-field level, three potential wells are observed where the approach of a positively charged reactant is favored. The first two (fig. 9 (1) ) at -2.9 $\mathrm{kcal} / \mathrm{mol}$ are associated with the $\mathrm{C}=\mathrm{C}$ bond. They lie symmetrically in planes parallel to that of the mole-
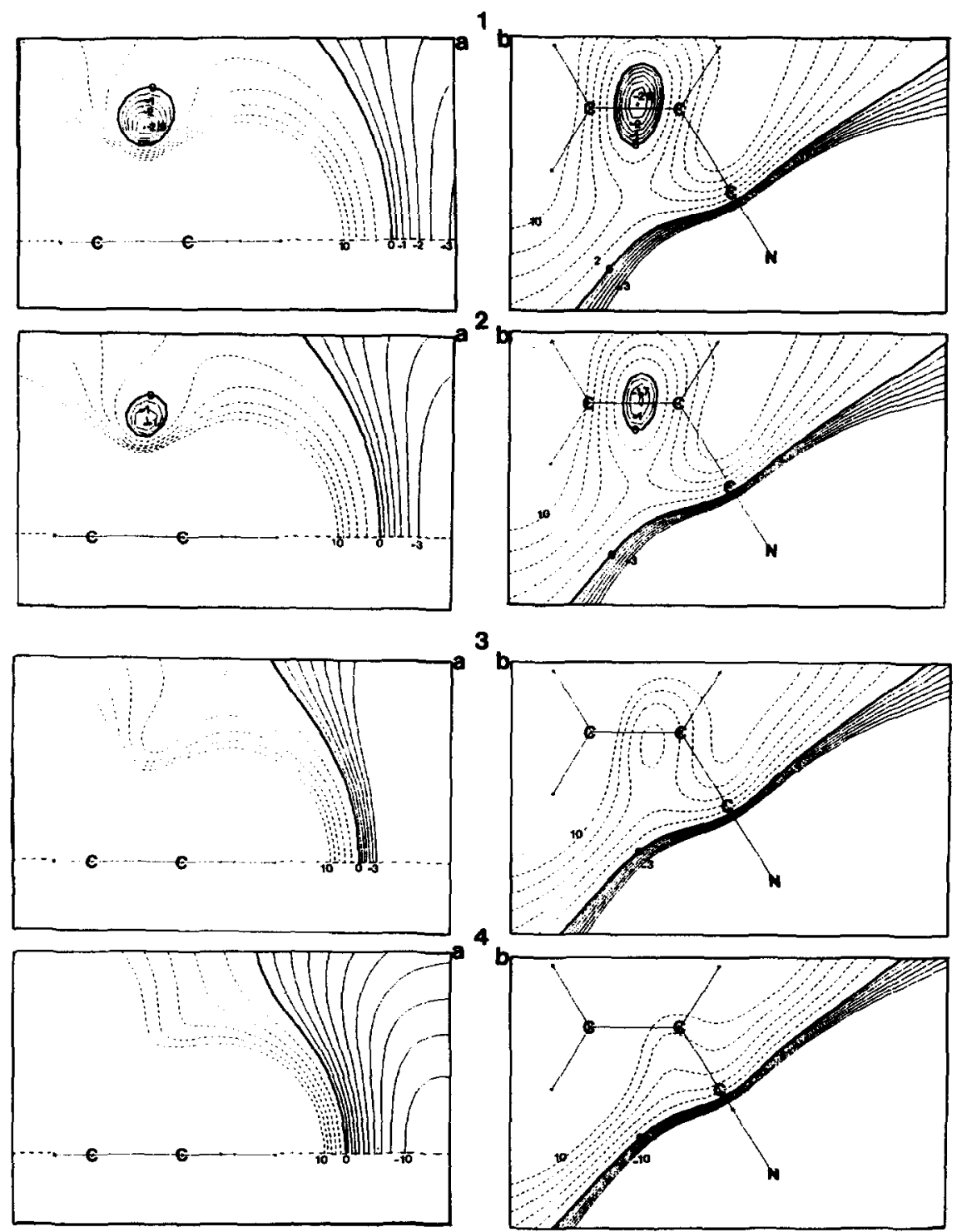

Fig. 9. Contour maps of the electrostatic potential: (a) in the $\pi_{0-c}$ plane, and (b) in a plane parallel to that of the molecule at a distance of $1.650 \AA$ for $E=0(1), 2.056 \times 10^{9}(2), 1.028 \times 10^{10}(3)$ and $2.056 \times 10^{10} \mathrm{~V} / \mathrm{m}(4)$. The interval between the isopotential curves is 2 $\mathrm{kcal} / \mathrm{mol}$ from 10 to $0 \mathrm{kcal} / \mathrm{mol}$ (dotted lines) and $0.5 \mathrm{kcal} / \mathrm{mol}$ (continuous lines), excepted in (4.a) where the negative curves are drawn from 0 to $-10 \mathrm{kcal} / \mathrm{mol}$ with a step of $1 \mathrm{kcal} / \mathrm{mol}$. 
cule at a distance of $\pm 1.65 \AA$ and correspond to the intuitive picture of the charge distribution of a $\mathrm{C}=\mathrm{C}$ bond. The occurrence of a lone pair on the nitrogen atom induces a large negative region near the $C \equiv N$ bond but without double minima. A deep well lies at $-56.3 \mathrm{kcal} / \mathrm{mol}$ in the plane of the molecule in agreement with a previously published work [18].

When the field intensity increases, the lone-pair well becomes deeper $(-111.8 \mathrm{kcal} / \mathrm{mol}$ at $E=2.056 \times$ $10^{10} \mathrm{~V} / \mathrm{m}$ ) and extends up to covering the entire $\mathrm{CN}$ bond. At the same time, the two $\mathrm{C}=\mathrm{C}$ bond wells vanish (this trend is shown in fig. 9). It suggests an overall increase of the positive character of the $\mathrm{CH}_{2}=\mathrm{CH}$ region of the molecule where the approach of a negatively charged reactant is favored, particularly for field intensity higher than $10^{10} \mathrm{~V} / \mathrm{m}$. The reactive character of $\mathrm{CH}_{2}=\mathrm{CH}$ is masked by the local importance of the electronic modification around the cyano group.

\section{Conclusion}

From the present study one can conclude that the application of strong electric fields (up to $2.056 \times 10^{10}$ $\mathrm{V} / \mathrm{m}$ ) on the acrylonitrile monomer induces negligible geometrical deformations and does not modify significantly the dipole moment direction (along the CN group).

For intensities up to about $5 \times 10^{9} \mathrm{~V} / \mathrm{m}$, the field effect on the electronic distribution is small: the $\mathrm{C}=\mathrm{C}$ double bond keeps the polarized character imposed by the high permanent dipole moment of the $\mathrm{CN}$ group in the absence of any applied field. For higher intensities, major effects are observed: a considerable increase of $\mu$ is reported together with a strong polarization of the $\mathrm{C}=\mathrm{C}$ bond. An opposite behaviour of the $\pi$ and $\sigma$ electrons is pointed out, the $\pi$ electrons following the field while the $\sigma$ electrons tend to counterbalance this effect. These opposite behaviours between $\sigma$ and $\pi$ electron transfer show how important is the $\sigma-\pi$ separation in conjugated system, suggesting that both systems must be analysed separately. Our study also suggests that the position "trans" to the cyano group is the most sensitive to the field.

So, it appears that the field in the electrochemical double layer does not significantly modify the reac- tivity of acrylonitrile, if it remains within the most commonly assumed values $\left(\approx 10^{9} \mathrm{~V} / \mathrm{m}\right)$. By contrast, if electric fields are higher than $5 \times 10^{9} \mathrm{~V} / \mathrm{m}$ there is a net increase in the electrophilic character of the $\mathrm{CH}_{2}$ terminal group and the opening of the $\mathrm{CC}$ bond is favoured through more efficient orbital interaction. Finally, the fact the the position trans to the $\mathrm{CN}$ group is mostly affected by the electric field gives a clue for an efficient of monitoring the electronic properties of the monomer in view of designing selective polymerization reactions.

\section{Acknowledgement}

JD and GH thank G. Lécayon and C. Boiziau (CEA) for stimulating discussions and acknowledge with appreciation the support of this work under the EURAM-EEC contract No. MAIE-0003-C. They also thank the Belgian National Fund for Scientific Research, IBM-Belgium, and the Facultés Universitaires Notre-Dame de la Paix for use of the Namur Scientific Computing Facility.

\section{References}

[1] H.D. Beckey, Field Ionisation Mass Spectrometry (Akademie-Verlag, Berlin, 1971).

[2] G. Naray-Szabo, P.R. Surjan and J.G. Angyan, Applied Quantum Chemistry (Reidel, Dordrecht, 1987).

[3] G. Lécayon, C. Reynaud, C. Boiziau, Y. Bouizem, C. Juret and C. Le Gressus, Chem. Phys. Letters 91 (1982) 506.

[4] G. Hennico, J. Delhalle, M. Raynaud, C. Reynaud and Y. Ellinger, Chem. Phys. Letters 152 (1988) 207.

[5] E. Scrocco and J. Tomasi, Topics Current Chem. 42 (1973) 95.

[6] J.S. Binkley, M.J. Frish, D.J. DeFrees, K. Raghavachari, R.A. Whiteside, H.B. Schlegel, E.M. Fluder and J.A. Pople, GAUSSIAN 82, Carnegic-Mellon University, Pittsburgh, PA (1981).

[7] H.D. Cohen and C.C.J. Roothaan, J. Chem. Phys. 43 (1965) 934.

[8] J.W. Mc Iver and A. Komornicki, Chem. Phys. Letters 10 (1971) 303;

P. Pulay, in: Methods of Electronic Structure Theory, ed. H.F. Schaefer III (Plenum Press, New York, 1977).

[9] R. Fletcher and M.J.D. Powell, Comput. J. 6 (1963) 163.

[10] K.B. Wiberg, J. Am. Chem. Soc. 102 (1980) 1229.

[11] W.J. Hehre, L. Radom, P. von R. Schleyer and J.A. Pople, Ab Initio Molecular Orbital Theory (Wiley, New York, 1986). 
[12] R.S. Mulliken, J. Chem. Phys. 23 (1955) 1833, 1841, 2338, 2343.

[13] C.C. Costain and B.P. Stoicheff, J. Chem. Phys. 30 (1959) 777.

[14] H. Nakatsuji, T. Hayakawa and T. Yonezawa, J. Am. Chem. Soc. 103 (1981) 7426;

L. Turi Nagy, I. Tvaroska and D. Tunega, Coll. Czech. Chem. Commun. 51 (1986) 1803;

J. Pancir and I. Haslingerova, Coll. Czech. Chem. Commun. 45 (1980) 2474;

J. Pancir and R. Zahradnik, Helv. Chim. Acta V 61 (1978) $1,3,59$;
V.V. Lobanov and M.M. Aleksankin, Intern. J. Mass Spectrom. Ion Phys. 18 (1975) 275.

[15] R.D. Nelson, D.R. Lide and A.A. Maryott, eds., Handbook of Chemistry and Physics, 65th Ed., Natl. Ref. Dat. Ser. NRSDS-NBS 10 (Natl. Bur. Stds., Washington, 1985) p. E58.

[16] E. Steiner, ed, The Determination and Interpretation of Molecular Wave Function (Cambridge Univ. Press, Cambridge) p. 148.

[17] K. Fukui, Accounts Chem. Res. 4 (1971) 57; Angew. Chem. Intern. Ed. 21 (1982) 801.

[18] R. Bonaccorsi, E. Scrocco and J. Tomasi, J. Am. Chem. Soc. 98 (1976) 4049. 